Editorial

\title{
Management of Multicompartmental Craniopharyngiomas: Combination of Concept, Technique, and Philosophy
}

\author{
Harjinder S. Bhatoe ${ }^{1}$ \\ ${ }^{1}$ Fortis Hospital, Noida, Uttar Pradesh, India \\ Indian J Neurosurg 2017;6:1-3.
}

The term "craniopharyngioma" was coined by Frazier and Alpers in 1931 to describe the developmental tumor that arises from the cell rests of the hypophyseal duct that fails to involute during the first trimester. ${ }^{1}$ The sellar and suprasellar region is a site of intense and precise actions in the first trimester, wherein the formation of adenohypophysis and neurohypophysis occurs in a definite sequence. Some of the cells rests can be found in the sella, suprasellar region, pituitary stalk, third ventricle, and posterior pharyngeal wall. Craniopharyngioma can develop at any of the sites and, depending on its growth, can manifest with visual loss, optic atrophy, growth disturbances, feeding and endocrinologic problems, disturbances in sexual function, and multiple cranial nerve palsy.

Craniopharyngiomas are slow-growing benign tumors, and the adjacent brain tissue reacts with intense gliosis and formation of Rosenthal fibers. ${ }^{2}$ Kawamata et $\mathrm{al}^{3}$ described the craniopharyngioma-brain interface that has a bearing on resectability of the tumor in contact with the hypothalamus. As per this description, type I tumors are characterized by encapsulated tumor with inflammation, facing a gliotic brain tissue. Type II shows a clear cleavage, and type III has interdigitating tumor margin into hypothalamus. Brain tissue layer adjoining the tumor is characterized with piloid gliosis and Rosenthal fibers. Their anatomical location with their proximity to visual apparatus, hypothalamus, and cranial nerves can result in severe visual, endocrine and cognitive deficits, and these deficits can occur due to surgical intervention too.

Surgical removal of craniopharyngiomas remains a challenge, even in this second decade of 21st century, more than 100 years after their removal was attempted. Cushing described craniopharyngiomas as "the kaleidoscopic tumors, solid and cystic, which take their origin from epithelial cell rests ascribable to an imperfect closure of hypophyseal or craniopharyngeal duct... whose management is one of the most baffling problems to the neurosurgeon." ${ }^{4}$ Hoffman described quite succinctly, the needed surgical attitude for their management, when he

Address for correspondence Harjinder S. Bhatoe, MCh, Fortis Hospital, B-22, Sector 62, Gautam Buddha Nagar, Noida, Uttar Pradesh 201301, India (e-mail: hsbhatoe@gmail.com). stated, “...perhaps the most important factor governing operative management of craniopharyngioma is the surgeon's attitude towards the tumor. If he or she regards the tumor as unresectable, it will be treated as such and no attempt will be made to remove it. If on the other hand, the surgeon feels the tumor that the craniopharyngioma can be totally removed, its management is likely to be successful." 5 The first attempt to remove these tumors is likely to be the best, whereas attempts to remove a previously operated and/or irradiated tumor will be difficult due to adherence of the tumor to the blood vessels, nerves, and hypothalamus. ${ }^{6}$ Thus, every attempt should be made to remove these tumors completely in the first surgery. The approach, a combination of frontal interhemispheric and trans-lamina terminal approaches gives an excellent view of the entire anatomy and pathology. ${ }^{7}$

Imaging displayed in the OR is studied (-Fig. 1), and the visible tumor anatomy is correlated with the imaging appearances. All components and lobulations of the tumor are identified and kept in mind as the dissection commences and planes get defined further. Subfrontal, subchiasmatic, and parasellar extensions are seen, and the extent of tumor growth and proposed excision is appreciated. No attempt should be made to coagulate the tumor surface. Following structures are displayed and will be repeatedly used as reference points as the dissection progresses:

- Optic chiasm, optic nerves, and tracts

- Arteries: Internal carotid, anterior choroidals, anterior cerebral and perforators in the optocarotid window, and those arising from A1 and internal carotid bifurcation

- Lamina terminalis

- As the dissection progresses, the oculomotor nerves, pituitary stalk and third ventricle, middle incisural space, and the posterior clinoid processes

The vascularity to craniopharyngiomas is provided by anterior circulation; there is no supply from basilar circulation. ${ }^{8}$ Opening of cerebrospinal fluid (CSF) cisterns and aspiration of cystic component of the tumor are vital to
DOI http://dx.doi.org/ 10.1055/s-0037-1601481. ISSN 2277-954X. (c) 2017 Neurological Surgeons' Society License terms of India 


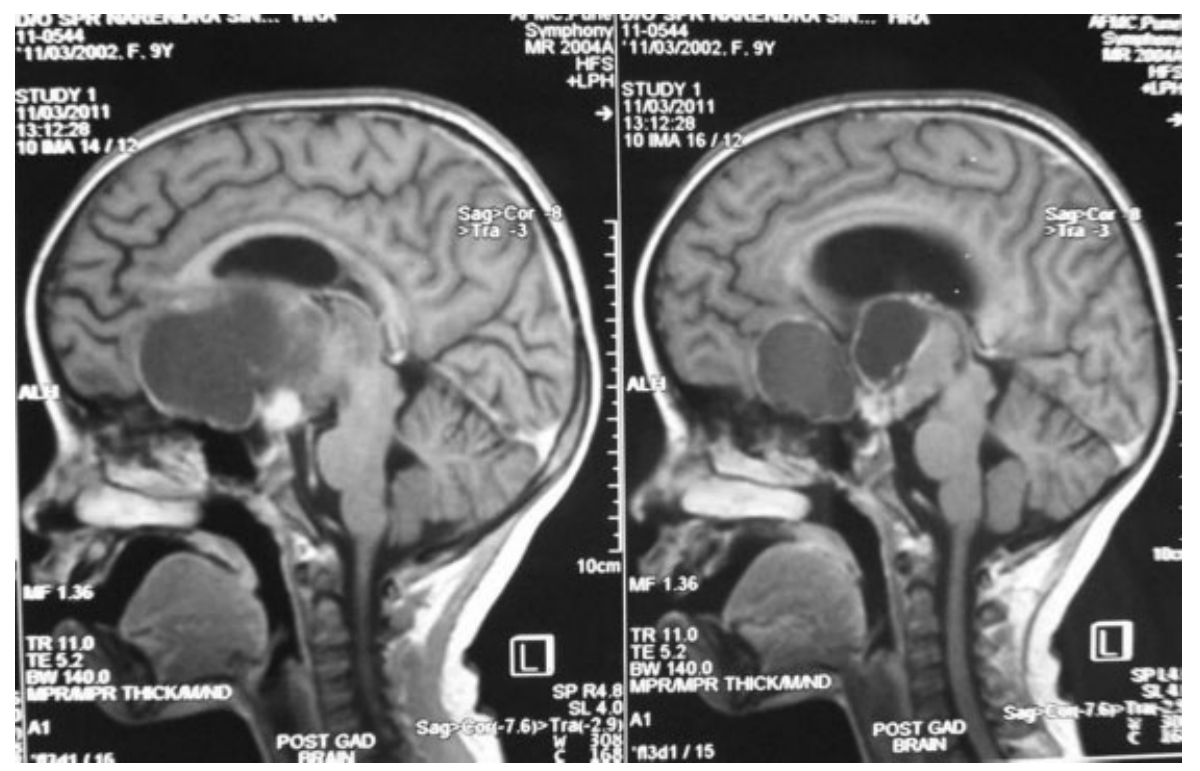

Fig. 1 MRI (T1-weighted, sagittal) showing multilobulated multicompartmental craniopharyngioma.

defining the pathology and anatomy and making a firm plan of action, as well as a contingency plan. For large retrochiasmatic and intra-third ventricular extensions, opening of lamina terminalis provides excellent visualization and preserves $A 1$ perforators to the hypothalamus (-Fig. 2). Attempt should be made to remove bulk of the tumor piecemeal through the lamina terminalis and prechiasmatic and lamina terminalis route (-Fig. 3). One should avoid opening the lateral corridors as far as possible to preserve perforators from the internal carotid, anterior choroidal, internal carotid artery (ICA) bifurcation, and A1. One must avoid "skeletonizing" these vessels, as the tumor is removed, and its diaphanous arachnoid covering should be preserved. Intra-third ventricular craniopharyngiomas can be removed by lamina terminalis approach, whereas pure intraventricular tumors ( $\mathbf{- F i g . ~ 4 )}$ are removed by standard approaches to anterior third ventricle. ${ }^{9}$

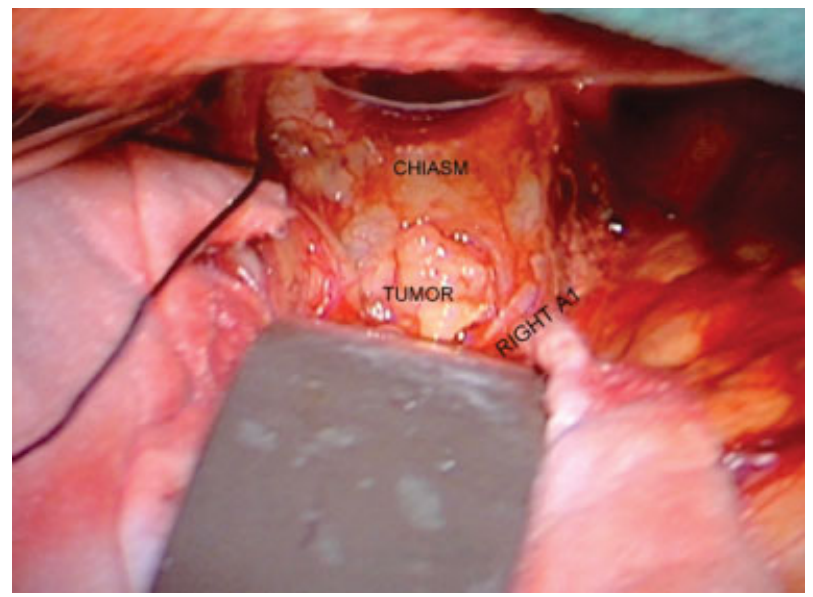

Fig. 2 Intraoperative appearance of a tumor being approached through lamina terminalis.

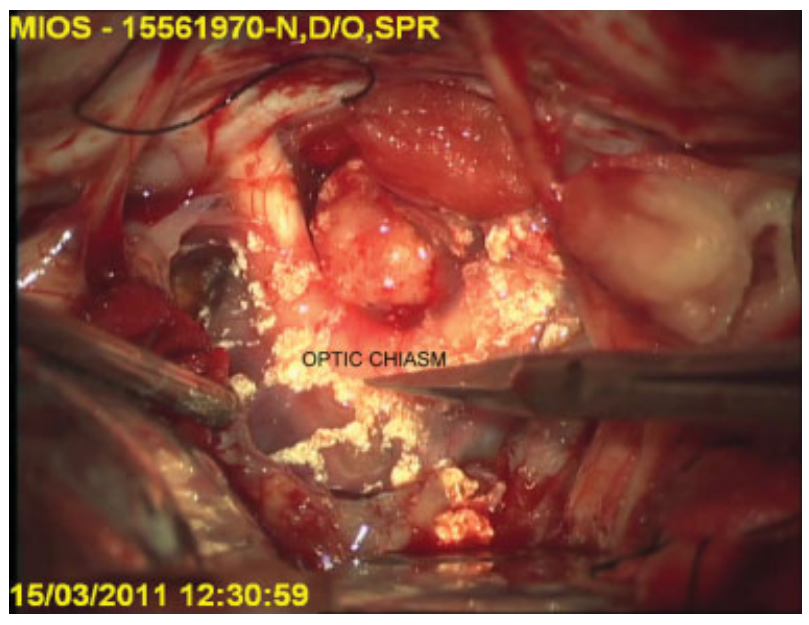

Fig. 3 Intraoperative appearance of tumor being separated from optic apparatus.

Despite the aim of total removal and attempts to preserve function, surgical morbidity in the form of disturbances of sensorium, electrolyte imbalance, visual disturbances, endocrine deficits, etc. remains high, and seemingly total resection does not guarantee cure. Hence there are alternative approaches described, which are less morbid but may result in significant residual tumor, necessitating radiotherapy, or radiosurgery. The latter too has morbidity that becomes evident as the children are followed up. Though there is huge volume of literature on pathogenesis and molecular pathology of craniopharyngiomas, results in terms of life expectancy and quality of life issues have not made comparative progress. The attempts, nevertheless, continue to excise these tumors microsurgically and control them by radiation, with endocrinologic management. 


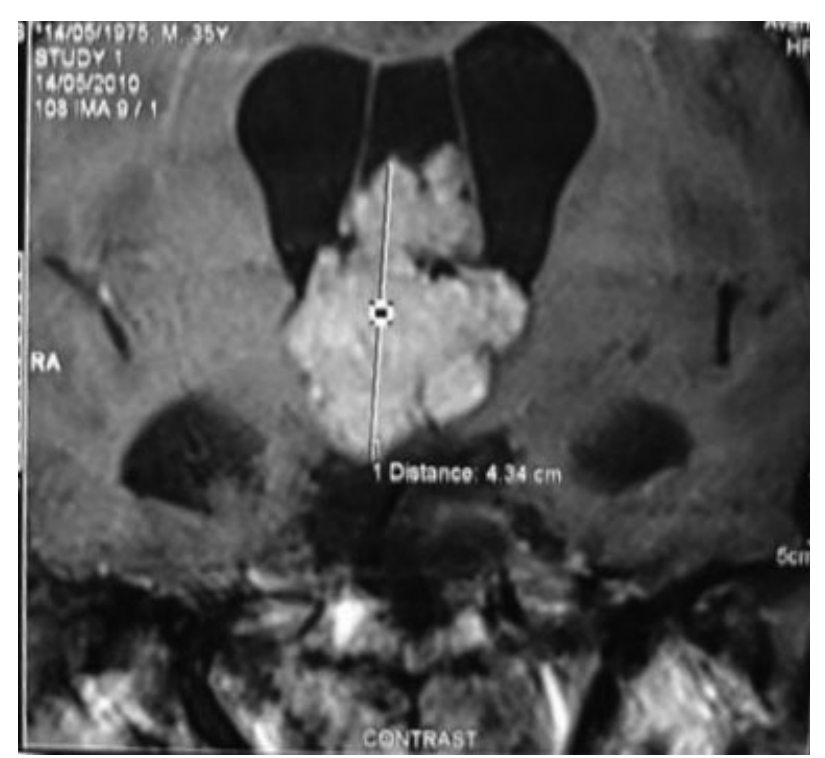

Fig. 4 MRI (T1-weighted, contrast-enhanced coronal section) showing intra-third ventricular craniopharyngioma.

\section{References}

1 Frazier $\mathrm{CH}$, Alpers BJ. Adamantinoma of the craniopharyngioma duct. Arch Neurol Psychiatry 1931;26:905-965

2 Janzer RC, Burger PC, Giangaspero F, Paulus W. Craniopharyngioma. In: Paul Kleihues, Webster KC, eds. Tumours of the Nervous System. Pathology and Genetics (World Health Organization Classification of Tumours). France: International Agency for Research on Cancer; 2000:244-246

3 Kawamata T, Kubo O, Hori T. Histological findings at the boundary of craniopharyngiomas. Brain Tumor Pathol 2005; 22(02):75-78

4 Cushing H. The craniopharyngiomas. In: Intracranial TumorsNotes upon a Series of Two Thousand Verified Cases with Surgical Mortality Percentages thereto. Springfield, IL: Charles C Thomas; 1932

5 Hoffman HJ. Surgical management of craniopharyngioma. Pediatr Neurosurg 1994;21(Suppl 1):44-49

6 Zuccaro G. Radical resection of craniopharyngioma. Childs Nerv Syst 2005;21(8-9):679-690

7 Dehdashti AR, de Tribolet N. Frontobasal interhemispheric trans lamina terminalis approach for suprasellar lesions. Neurosurgery 2005;56(ONS supplement 2):ONS418-ONS424

8 Albright AL. Craniopharyngiomas. In: Black PM, Loeffler JS, eds. Cancer of the Nervous System. 2nd ed. Philadelphia, PA: Lippincott Williams \& Wilkins; 2005:445-452

9 Bhatoe HS, Deb P, Sengupta SK. Synchronous morphologically distinct craniopharyngioma and pituitary adenoma. A rare entity. Brain Disord Ther 2016;5:207-209 